\title{
Coating porous membranes with a photocatalyst: Comparison of LbL self-assembly and plasma-enhanced CVD techniques
}

submitted for consideration as a publication in the Journal of Membrane Science

by

Brian J. Starr ${ }^{1}$, Volodymyr V. Tarabara ${ }^{1 *}$, Ming Zhou ${ }^{2}$, Stéphanie Roualdès ${ }^{2}$, André Ayral $^{2}$

1 Department of Civil and Environmental Engineering, Michigan State University, East Lansing, MI 48824, USA

2 Institut Européen des Membranes, CNRS-ENSCM-UM, cc047, Université de Montpellier, Place Eugène Bataillon, F-34095 Montpellier cedex 5, France

April 10, 2016

${ }^{*}$ Corresponding author 


\section{Abstract}

Two methods for coating a microporous surface of a membrane support layer with a photocatalyst are comparatively evaluated. Layer-by-layer self-assembly of nanoTiO ${ }_{2}$ with a multilayer of poly(diallyldimethylammonium chloride) and poly(acrylic acid) as a binder produces a sub-monolayer of photocatalyst nanoparticles on the grains of the membrane support. In contrast, plasma-enhanced chemical vapor deposition gives a dense uniform coating on the membrane grains. Neither method reduces membrane permeability. The photocatalytic activity of the coated membranes was evaluated in filtration tests with methylene blue as a probe compound. To compare photocatalytic performance of the two coatings, measured values of the reactive flux $(\eta, \mathrm{m} / \mathrm{s})$ were normalized by reaction rate constants $\left(k^{\prime \prime}, \mathrm{m} / \mathrm{s}\right)$ determined in batch tests with the same catalyst. The proposed modeling approach relates coating's reactivity ( $\eta$ and $\left.k^{\prime \prime}\right)$ to the reactor's geometry expressed in terms of the length of the reaction zone $\left(l^{r z}\right)$ and coating density $(\theta)$. Both coating techniques result in a similar coating quality as witnessed by similar values of $\eta / k^{\prime \prime}$ (or, equivalently, similar values of $\theta l^{r z}$ ). The proposed analysis offers insights into possible ways for improving each coating technique.

Keywords: photocatalysis; photocatalytic membrane reactors; layer-by-layer; plasmaenhanced chemical vapor deposition; performance modeling 


\section{Introduction}

Application of titanium dioxide $\left(\mathrm{TiO}_{2}\right)$ photocatalysis in water treatment and environmental remediation has been an active area of research due to the ability of $\mathrm{TiO}_{2}$-catalyzed reactive oxygen species to mineralize organic pollutants [1-3]. While $\mathrm{TiO}_{2}$ photocatalytic processes have seen commercial adoption in fields such as air purification, photocatalysis-based water treatment technologies face many challenges [4]. Batch reactors with suspended catalyst require additional separation step to recover the catalyst while the performance of fixed bed photocatalytic reactors may be mass transfer limited. Combining membrane separation and photocatalysis into a single hybrid process may overcome such limitations $[5,6]$.

Research has focused on coupling the separation and catalytic functionalities, where the catalyst is integrated into the selective layer of the membrane. The coupling helps concentrate pollutant near the catalyst surface and reduce membrane fouling. Thus, in most studies photocatalytic coatings have been formed on the feed side of the membranes. The only studies where the coating was on the permeate side were reports by Ayral and colleagues [7-9], by Romanos and colleagues [10-14] and by

Guo et al. [15]. Permeate side photocatalysis (Figure 1) has several benefits. First, the photocatalytic and separation functionalities are decoupled and can be optimized independently. Second, such decoupling increases process robustness wherein a failure in one of the functions (photocatalysis or selective separation) does not 
necessarily result in a loss of both. Third, membrane's selectivity can be tuned to minimize catalyst fouling. The permeate stream has increased transparency and therefore affords a higher photocatalytic efficiency.

Various coating approaches have been employed to create photocatalytic layers on membrane surfaces, including dip coating, layer-by-layer (LbL) assembly, sol-gel, and chemical vapor deposition (CVD) [16-19]. Recently, plasma-enhanced chemical vapor deposition (PECVD) has been used to create skin coatings on surface grains of porous supports at low temperatures [9]. Lower temperatures translate into reduced energy demand compared with traditional CVD and allow for deposition on temperature sensitive substrates. LbL self-assembly has been used to create various $\mathrm{TiO}_{2}$ film morphologies, but to date has not been applied to coat the typically very porous permeate surface of water filtration membranes.

The present study compares permeabilities and reactivities of ceramic membranes with photocatalytic permeate surface coated using LbL and PECVD techniques. We employ batch reactions with a model pollutant (methylene blue, MB) to determine the photoactivity of each catalyst. We then measure MB degradation in a photocatalytic membrane reactor to compare the quality of the two types of coating. 


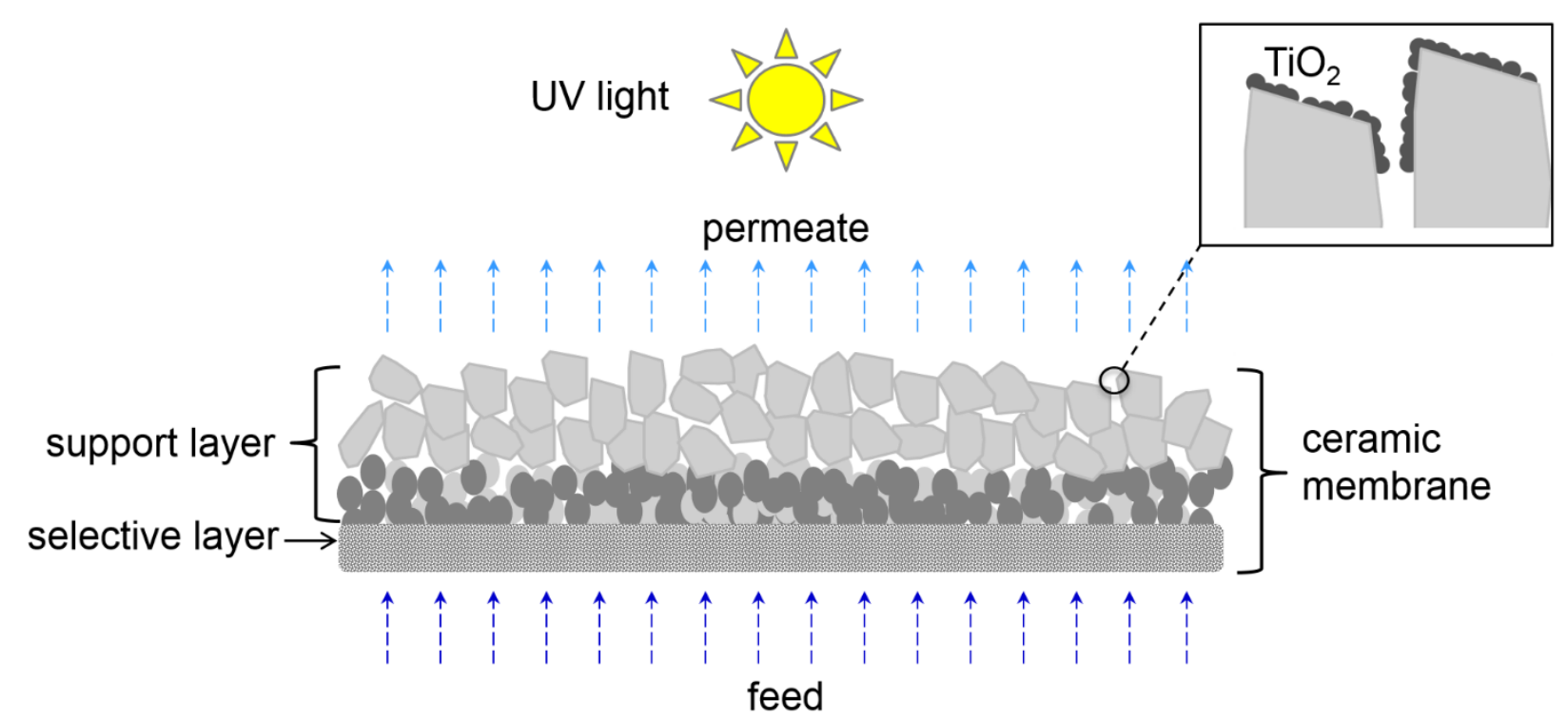

Figure 1: Schematic illustration of a cross-section of an asymmetric ceramic membrane with the permeate side coated by catalytic nanoparticles and exposed to UV light for flow-through photocatalysis. 


\section{Approach}

\subsection{Fabrication of photoactive membrane layer}

LbL assembly exploits the surface charge of polyelectrolytes to adhere suspended catalytic nanoparticles to a surface. This process includes two steps: i) applying polyelectrolytes (PE) to the surface, and then ii) exposing the polyelectrolyte-modified surface to a nanoparticle suspension to enable particle adhesion to the polyelectrolyte-coated surface. The morphology of the resulting coating depends on the deposition conditions (e.g. pH and ionic strength of the catalyst suspension, the degree of PE ionization) and properties of surfaces involved (e.g. the charge and hydrophilicity of nanoparticles and the membrane). The amount of catalyst surface aggregation is a balance between the electrostatic repulsion between catalyst particles and the attractive force between the negatively charged terminating PE and the positively charged catalyst. To ensure the positive charge on the catalyst, it is dispersed at a pH below its point of zero charge (PZC) (for $\mathrm{TiO}_{2}, \mathrm{PZC}$ is in the range from $\mathrm{pH} 5$ to $\mathrm{pH} 7$ [20].) PE-catalyst interaction was manipulated by adjusting $\mathrm{pH}$ to vary $\mathrm{PE}$ and $\mathrm{TiO}_{2}$ nanoparticle charges. The $\mathrm{LbL}$ self-assembly employed commercially available photocatalyst nanoparticles known to have high photoactivity.

The PECVD method has been developed [9] as a means of creating skin coverage of 
$\mathrm{TiO}_{2}$ on surface grains of porous supports. This method uses chemical vapor deposition with the aid of plasma to oxidize titanium dioxide precursors on a substrate. $\mathrm{TiO}_{2}$ in post-annealed PECVD coatings is $100 \%$ anatase [9]. Both fabrication methods were applied to the same porous ceramic support to enable a more accurate comparison.

\subsection{Quantifying reaction rate constants in batch and membrane reactors}

\subsubsection{Batch reactions}

The removal of MB in a batch reactor depends on the concentration of both $\mathrm{MB}$ and reactive oxygen species, ROS:

$$
\frac{d[M B]}{d t}=K_{b}[M B][R O S]
$$

Assuming that the concentration of reactive oxygen species is constant, eq. (1) simplifies to:

$\frac{d[M B]}{d t}=k_{b}^{\prime}[M B]$

where $k_{b}^{\prime}=K_{b}[R O S]$ is the observed pseudo- $1^{\text {st }}$ order reaction constant that can be 
measured in batch reactor tests. Normalizing constant $k_{b}^{\prime}\left(\mathrm{s}^{-1}\right)$ by the specific surface area of photocatalyst in the batch reactor, $s_{b}\left(\mathrm{~m}^{2} / \mathrm{m}^{3}\right)$, gives another constant, $k^{\prime \prime}(\mathrm{m} / \mathrm{s})$, which can serve as an intrinsic metric of catalyst reactivity:

$k^{\prime \prime}=\frac{k_{b}^{\prime}}{s_{b}}$

We note that the ROS concentration $\left(\mathrm{mol}_{\mathrm{ROS}} / \mathrm{m}^{3}\right)$ is a product of the specific surface area of photocatalyst in the reactor, $s_{b}$, and the catalyst yield, $Y\left(\mathrm{molROS} / \mathrm{m}^{2}\right)$ :

$[R O S]=Y s_{b}$

Substituting eq. (3b) into the definition of $k_{b}^{\prime}$ gives:

$k_{b}^{\prime}=K_{b} Y s_{b}$

and eq. (3a) can be rewritten as

$k^{\prime \prime}=K_{b} Y$

Assuming that catalyst particles are spherical and that the suspension is monodisperse, the specific surface area of suspended catalyst in a batch reactor is given by:

$s_{b}=\frac{3}{a} \frac{V_{\mathrm{TiO}_{2}}}{V_{b}}=\frac{3}{a} \frac{1}{V_{b}} \frac{M_{\mathrm{TiO}_{2}}}{\rho_{\mathrm{TiO}_{2}}}$

where $V_{b}$ is the volume of the batch reactor, $a$ is the radius of the spherical catalyst 
particle, and $\mathrm{M}_{\mathrm{TiO}_{2}}$ is catalyst loading (i.e. the total mass of catalyst in the reactor). Substituting eq. (4) into eq. (3a) gives:

$$
k^{\prime \prime}=\frac{k_{b}^{\prime}}{s_{b}}=k_{b}^{\prime} \frac{V_{b} \rho_{\text {TiO }_{2}}}{3 M_{\text {TiO }_{2}}} a
$$

\subsubsection{Photocatalytic membrane reactor}

In a membrane reactor, the reaction occurs within the membrane pore space. Herein we approximate membrane pores as straight-through and cylindrical with diameter $d_{\text {pore }}$ (Figure 2). Further, we consider the membrane as an ideal plug-flow reactor where the reaction occurs only in the reaction zone defined as the part of the pore space where both catalyst and UV light are available. Eq. (3a) can be rewritten for the case of membrane reactor as follows:

$$
k^{\prime \prime}=\frac{k_{p f}}{s_{p f}}
$$

where $k_{p f}(\mathrm{~m} / \mathrm{s})$ is the $1^{\text {st }}$ order reaction constant in the plug-flow membrane reactor and $s_{p f}\left(\mathrm{~m}^{2} / \mathrm{m}^{3}\right)$ is the specific surface area of photocatalyst in the reaction zone of the membrane reactor. 

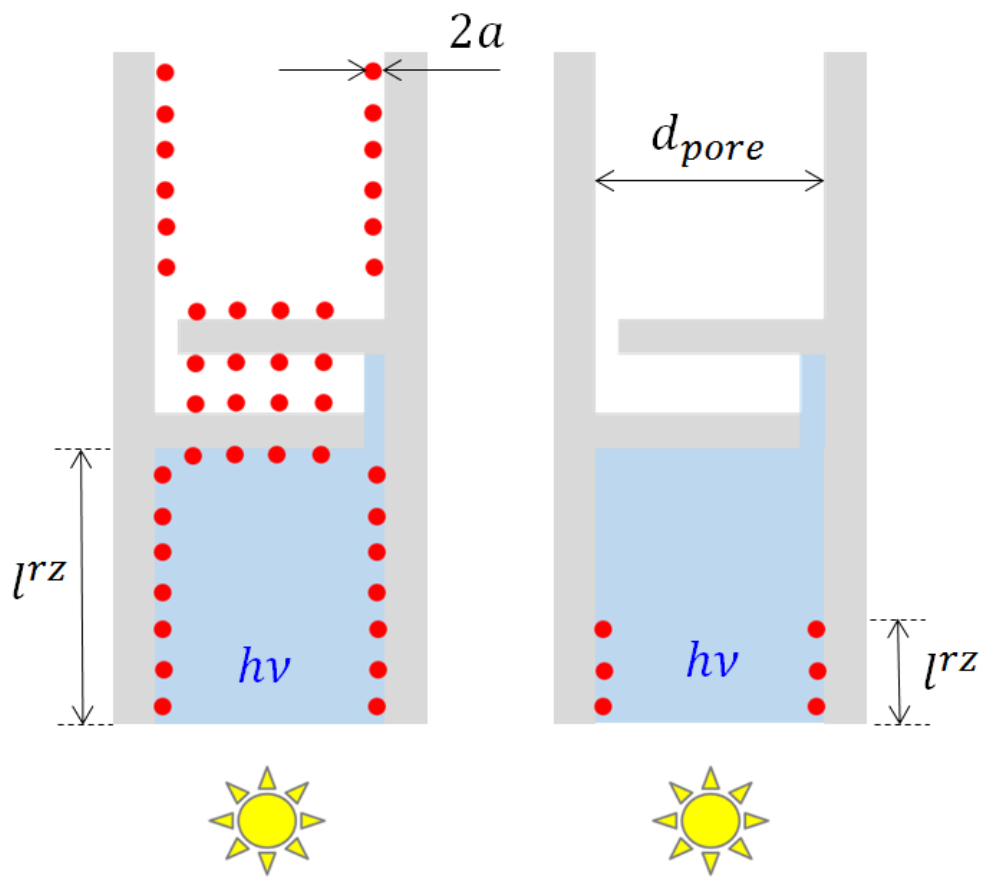

Figure 2: Schematic representation of two cylindrical pores of diameter $d_{\text {pore }}$ covered with catalyst particles of diameter $2 a$. The reaction zone in each pore is of depth $l^{r z}$. Reaction zone is defined as the part of the pore where both photocatalyst and light are present.

For the purpose of comparing different membrane reactors, it is convenient to introduce a ratio, $\theta$, of the specific surface area of the catalyst to the specific surface area of the reaction zone:

$\theta=s_{p f} \frac{V_{r z}}{S_{r z}}$

where $V_{r z}$ and $S_{r z}$ are the volume and the total surface area of the reaction zone, respectively. For cylindrical pores

$\theta=s_{p f} \frac{d_{p o r e}}{4}$

and eq. (6) can be recast as 


$$
k_{p f}=k^{\prime \prime} \frac{4 \theta}{d_{\text {pore }}}
$$

The extent of reaction in an ideal plug-flow reactor with a $1^{\text {st }}$ order reaction is given by

$$
\ln \left(\frac{C}{C_{0}}\right)=-k_{p f} \tau
$$

where $C_{0}$ and $C$ are reactant's concentrations in the feed and effluent, and $\tau$ is residence time within the reactor. For cylindrical straight-through pores, $\tau$ is a ratio of the length of the reaction zone, $l^{r z}$, to the volumetric permeate flux, $j(\mathrm{~m} / \mathrm{s})$ so that

$$
\ln \left(\frac{C}{C_{0}}\right)=-k_{p f} \frac{l^{r z}}{j}=-\frac{\eta}{j}
$$

where the product of $k_{p f}$ and $l^{r z}$ can be interpreted as reactive flux (m/s) [21, 22]:

$$
\eta=k_{p f} l^{r z}
$$

Eq. (9b) can be used to determine $\eta$ experimentally in simple dead-end filtration experiments where the coated side of the membrane is exposed to UV light. By plotting $\ln \left(\frac{C}{C_{0}}\right)$ against the inverse of permeate flux, reactive flux $\eta$ can be obtained. Substituting eq. (8) into eq. (10) gives an expression that connects geometrical properties of a membrane reactor $\left(l^{r z}\right.$ and $\theta$ ) with reactivity characteristics that can be determined experimentally $\left(k^{\prime \prime}\right.$ and $\left.\eta\right)$ : 
$l^{r z} \theta=\frac{\eta}{k^{\prime \prime}} \frac{d_{\text {pore }}}{4}$

or

$\frac{\eta}{k^{\prime \prime}}=4 \frac{l^{r z} \theta}{d_{\text {pore }}}$

Equation (11b) relates reactivity of the membrane reactor (left hand side) to geometric parameters of the reaction zone (right hand side). The relationship assumes a cylindrical pore coated with spherical catalytic particles. Because of these highly idealistic assumptions, the model does not enable a quantitative description of catalytic membrane coatings in absolute terms. However, it enables a semi-quantitative comparison of coatings and can offer insights into relative advantages of different coating techniques.

Assuming that two coatings are applied to identical membrane supports and that neither coating reduces the pore diameter, eq. (11b) gives:

$\frac{l_{x}^{r z}}{l_{y}^{r z}} \frac{\theta_{x}}{\theta_{y}}=\frac{\eta_{x}}{k_{x}^{\prime \prime}} \frac{k_{y}^{\prime \prime}}{\eta_{y}}$

where indexes $x$ and $y$ refer to two different coating methods. A longer reaction zone (i. e. larger $l^{r z}$ ) and a denser coating (i.e. larger $\theta$ ) should results in a more efficient photocatalytic reactor. The fact that reactive fluxes in eq. (12) are normalized by corresponding reaction constants underscores that the equation serves to compare coating geometries. In the case of LbL and PECVD techniques 
referenced with indexes " 1 " and "2" respectively, a ratio $\frac{l_{1}^{r z}}{l_{2}^{r z}} \frac{\theta_{1}}{\theta_{2}}$ greater than 1 should indicate that the LbL method yields a higher quality coating. Conversely, $\frac{l_{1}^{r z}}{l_{2}^{r z}} \frac{\theta_{1}}{\theta_{2}}$ smaller than 1 indicates that PECVD results in a better coating. Herein high quality refers to both larger catalyst surface area and optimal placement of the catalyst. The length of the reaction zone is a function of both pore morphology and the depth of coating.

\section{Experimental}

\subsection{Reagents}

Polyelectrolytes used for the LbL deposition of catalyst included reagent grade polydiallyldimethylammonium chloride (PDADMAC, Aldrich, MW 100,000-200,000), poly(acrylic acid) (Aldrich, MW 1,800), poly(sodium styrene sulfonate) (PSS, Aldrich, MW 70,000), and poly(allylamine hydrochloride) (PAH, Aldrich, MW 70,000).

Commercially available titanium dioxide (Evonik P25) was used as a catalyst in LbL self-assembly. Titanium tetra-isopropoxide (TTIP) (Sigma-Aldrich) was used as a precursor in plasma-enhanced chemical vapor deposition coatings. Methylene blue (Sigma) served as a model pollutant in both batch and photocatalytic filtration experiments. Potassium iodine (Jade Scientific), iodate (EM Industries), and borate buffer (Sigma-Aldrich) solutions were used in chemical actinometry to quantify UV fluence $[15,23]$. Flat disc membranes (TAMI Industries, FR) with a nominal pore 
size of $0.14 \mu \mathrm{m}$ were used as porous supports. All disks were cleaned in nitric acid (EMD Performance Materials) and sodium hydroxide (Sigma-Aldrich) solutions. Glass slides were cleaned with detergent (Alconox), hydrochloric acid (EDM Performance Materials), and acetone (Sigma-Aldrich). Piranha solution was prepared with a mixture of sulfuric acid (J.T. Baker) and hydrogen peroxide (Fisher Scientific). Additionally, hydrochloric acid (EMD Performance Materials) and sodium hydroxide (Sigma-Aldrich) were used for pH adjustments.

\subsection{Layer-by-layer assembly}

Initially, LbL deposition was performed on glass slides (VWR, 24x60 mm). The slides were cleaned by consecutively sonicating in solutions of detergent, hydrochloric acid, and acetone. After cleaning, the slides were submerged into a 3:1 mixture of sulfuric acid and hydrogen peroxide for a minimum of $12 \mathrm{~h}$. The clean slides were alternately dip coated in anionic and cationic $0.02 \mathrm{M}$ solutions of polyelectrolytes. After each layer of polyelectrolyte, the samples were rinsed with DI water. Two types of polyelectrolyte multilayers were deposited: [PAH/PSS] and [PDADMAC/PAA]. With both systems, cationic polyelectrolytes (PAH, PDADMAC) were used as initiating layers and anionic polyelectrolytes (PSS, PAA) were used as the terminating layer. A complete PEM consisted of 4 bilayers, with each bilayer having 1 anionic and 1 cationic polyelectrolyte. After coating 4 bilayers of polyelectrolytes, the glass slides were dried in a gentle stream of compressed air. 
The polyelectrolyte-coated slides were then submerged in a $300 \mathrm{mg} / \mathrm{L}$ suspension of P25 photocatalyst for 30 min. To prepare the catalyst suspension, the $\mathrm{TiO}_{2}$ was suspended in DI water and sonicated using a bath sonicator. Prior to sonication, the $\mathrm{pH}$ of the catalyst suspension was adjusted to match the $\mathrm{pH}$ of the solution from which the terminating polyelectrolyte layer was deposited. Catalyst was suspended in $0.01 \mathrm{M}$ ionic strength solution and in DI water to investigate double layer charge compression effects on deposited catalyst morphology.

The porous membranes were cleaned prior to coating by soaking for $30 \mathrm{~min}$ in $20 \mathrm{~g} / \mathrm{L}$ $\mathrm{NaOH}$ at $80^{\circ} \mathrm{C}$, followed by soaking for $15 \mathrm{~min}$ in $5 \mathrm{~mL} / \mathrm{L} \mathrm{HNO}_{3}$. The first LbL-coated membrane was prepared with $[\mathrm{PDADMAC} / \mathrm{PAA}]_{4}$ and 1 layer $\mathrm{TiO}_{2}$. The $\mathrm{pH}$ of the PAA solution and $\mathrm{TiO}_{2}$ were adjusted to 5 and the $\mathrm{TiO}_{2}$ suspension had zero ionic strength (DI water). Additionally, a second membrane was prepared with 5 total layers of $\mathrm{TiO}_{2}$ by repeated deposition of $[\mathrm{PDADMAC} / \mathrm{PAA}]_{4}$ and $\mathrm{TiO}_{2}$. During coating, only the support structure of the membrane was exposed to polyelectrolytes and catalyst. Following deposition of catalyst, the deposited layers were thermally treated at $500^{\circ} \mathrm{C}$ for $45 \mathrm{~min}$ (RHF 15/3, Carbolite Ltd).

\subsection{Plasma-enhanced chemical vapor deposition}

Photocatalytic membranes fabricated with PECVD were prepared using flat disc 
ceramic membranes of the same kind as the ones used with the LbL technique. Membranes were coated using a process previously developed and optimized [9]. Prior to the deposition of catalyst, the membranes were cleaned by soaking for 30 min in $20 \mathrm{~g} / \mathrm{L} \mathrm{NaOH}$ at $80^{\circ} \mathrm{C}$, followed by soaking for $15 \mathrm{~min}$ in $5 \mathrm{ml} / \mathrm{L} \mathrm{HNO}$. The membrane was then placed in the PECVD deposition chamber and a vacuum was applied. The membrane was heated to $150^{\circ} \mathrm{C}$ and maintained at this temperature throughout the deposition process. Using argon as a carrier gas, TTIP (the precursor) conditioned at $80^{\circ} \mathrm{C}$ in an oil bath was fed to the chamber along with oxygen. The carrier gas line was heated to $100^{\circ} \mathrm{C}$ to prevent condensation of the precursor. The flux ratio of TTIP to oxygen (controlled by the partial pressures ratio in the plasma chamber equal to $0.225 \mathrm{mbar} / 0.17 \mathrm{mbar}$ ) had been previously optimized for maximum growth rate, thickness homogeneity and Ti-O abundance [15]. A radio-frequency $(13.56 \mathrm{MHz})$ induced plasma with an input power of $50 \mathrm{~W}$ was applied for 20 min, resulting in the formation of a layer of $\mathrm{TiO}_{2}$ catalyst on the substrate. The feed side of the membrane was placed face down in the coating apparatus but was not sealed off from the plasma; yet there was no visual indication of coating anywhere other than on the support side of the membrane. The deposition process was implemented once to create one-layered membrane or twice to prepare two-layered membranes. Finally, the membranes were finally thermally treated at $300^{\circ} \mathrm{C}$ for 300 min (Ney Vulcan 3-130).

\subsection{Photocatalysis in a batch reactor}


The photocatalytic efficiency of commercial P25 catalyst and PECVD-generated catalysts was measured in a UV batch reactor. The batch reactor consisted of a UV exposure chamber, UV lamp (16 W, model GPH330T5L/4, Atlantic Ultraviolet Corp), stir plate, and a beaker (Figure 3A). The UV lamp emitted within the germicidal range, with $95 \%$ of emitted energy at the $254 \mathrm{~nm}$ wavelength. Batch experiments with P25 and PECVD-generated catalysts were conducted using MB as a model pollutant. The catalyst slurry was prepared by suspending catalyst particles in DI water and adjusting the $\mathrm{pH}$ using $\mathrm{HCl}$. The $\mathrm{P} 25$ suspension had $\mathrm{pH} 4$ and the PECVD-generated catalyst had pH 3.1. MB was added to the catalyst suspensions and allowed to equilibrate for 30 minutes prior to UV exposure. During the batch test, the fluid remained stirred and samples were taken at periodic intervals of UV exposure.

To prepare PECVD-generated catalyst powder, thin layers of catalyst were deposited on silicon wafers and thermally treated at $500^{\circ} \mathrm{C}$ for $1 \mathrm{~h}$. Using a micro-spatula, the coatings were then scraped to generate loose powder. This powder was suspended in DI water and sonicated for $2 \mathrm{~h}$. The particle size distribution of the suspended catalyst was measured prior to MB experiments (Brookhaven, ZetaPALS). 


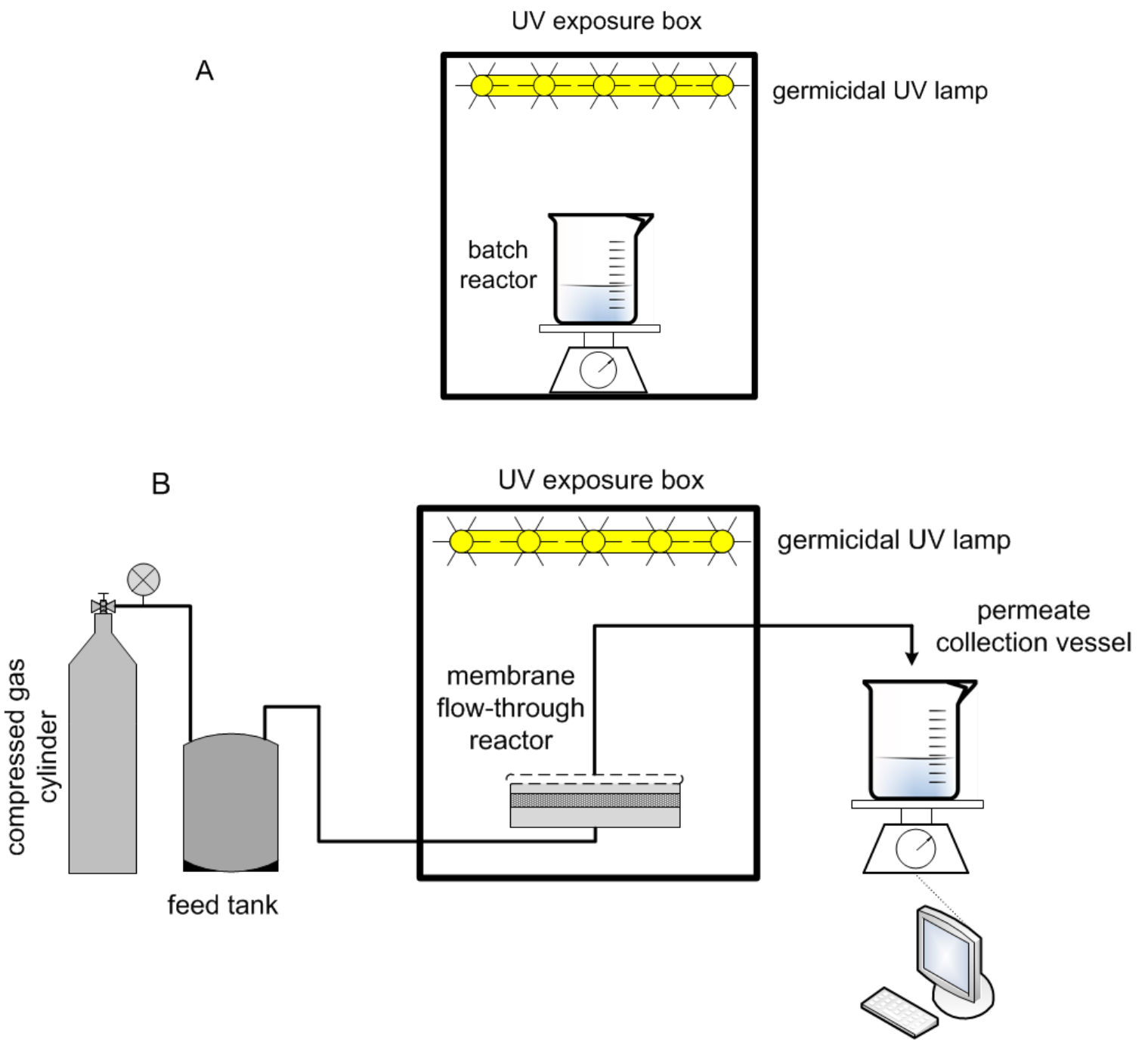

Figure 3: UV batch reactor $(A)$ and photocatalytic membrane reactor $(B)$ used to evaluate photocatalyst efficiency and performance of the UV-microfiltration hybrid process.

\subsection{Photocatalysis in a membrane reactor}

Photocatalytic membrane reactor (Figure 3B) was constructed by machining a permeate window in a $47 \mathrm{~mm}$ diameter stainless steel dead-end filtration cell (Sterlitech). A 1/8" thick quartz glass disc (Technical Glass Products) was fit into the 
window with a glass hose barb to capture the permeate stream. During dead-end filtration experiments, the membrane holder was positioned such that the permeate window was uniformly exposed to UV light. Photocatalytic membrane reactor tests utilized the same UV exposure box and UV lamp as the batch reaction experiments. All filtrations were conducted in the constant pressure regime. The first stage of filtration was performed in the absence of UV until a constant permeate concentration of MB was achieved. After reaching a steady permeate concentration, the permeate was exposed to UV through the quartz window and permeate samples were collected at regular intervals. Flux was recorded using a data acquisition system.

\subsection{Measuring concentration of Methylene Blue}

Methylene Blue absorbance, $A$, was measured at $663 \mathrm{~nm}$ and converted to MB concentration using the Beer-Lambert law:

$A=\varepsilon C_{M B} l$

where $\varepsilon$ is the molar absorption coefficient, $C_{M B}$ is the molar concentration of MB, and $l$ is the optical path length. A molar absorption coefficient of $69,362 \mathrm{~L} /(\mathrm{mol} \cdot \mathrm{cm})$ at $663 \mathrm{~nm}$ was determined by measuring the absorbance (MultiSpec, 1501, 
Shimadzu) from a series of MB dilutions. The optical path length was $1 \mathrm{~cm}$.

\subsection{UV fluence quantification}

The UV fluence was measured using chemical actinometry. A stock solution of 0.1 $\mathrm{M}$ iodate and $0.01 \mathrm{M}$ sodium borate was prepared and the $\mathrm{pH}$ was adjusted to 9.3. For each sample, $100 \mathrm{~mL}$ of stock solution was added to a beaker with $0.6 \mathrm{M}$ potassium iodide. The sample was placed in the UV exposure chamber and exposed to UV light while under continuous stirring for a given period of time. The absorbance at $352 \mathrm{~nm}$ of an irradiated and non-irradiated baseline sample were measured. The fluence, $F\left(\mathrm{~J} / \mathrm{cm}^{2}\right)$ is calculated as [24]:

$$
F=\frac{v A_{352} V}{\varepsilon_{352} S \Phi}
$$

where $v=4.72 \cdot 10^{5} \mathrm{~J} / \mathrm{E}$ is a conversion factor, $A_{352}$ is absorbance at $352 \mathrm{~nm}, V$ is sample volume, $\varepsilon_{352}=26,400 \mathrm{~L} / \mathrm{mol}$ is the molar absorption coefficient at $352 \mathrm{~nm}, S$ is the exposed surface area, $\mathrm{cm}^{2}$, and $\Phi$ (mol/Ein) is the quantum yield given by eq. (15), where $T$ is temperature in Celsius and $C$ is the molar concentration [23].

$$
\Phi=0.75[1+0.02(T-20.7)][1+0.23(C-0.577)]
$$




\subsection{Scanning electron microscope imaging}

Scanning electron microscopy (SEM) images of the LbL-coated glass slides, LbL-coated membranes and PECVD-coated membranes were recorded (JEOL 6610LV SEM) under various magnifications. Samples of LbL-coated membranes and glass slides were mounted onto aluminum stubs and sputtered with $\sim 20 \mathrm{~nm}$ thick layer of gold (Emscope Sputter Coater, model SC 500, Quorum Technologies) prior to SEM imaging. PECVD-coated membranes were imaged directly, bypassing the step of sputtering by gold.

\section{Results and Discussion}

The as-purchased membranes consisted of three sublayers of different porosities

(Figure 4). As reported by the manufacturer and confirmed by EDS analysis (see Supplementary Material (SM), Figure S1), the most porous and intermediate porosity sublayers were made of $\mathrm{TiO}_{2}$ while the skin layer was $\mathrm{TiO}_{2} / \mathrm{SrO}_{2}$. 

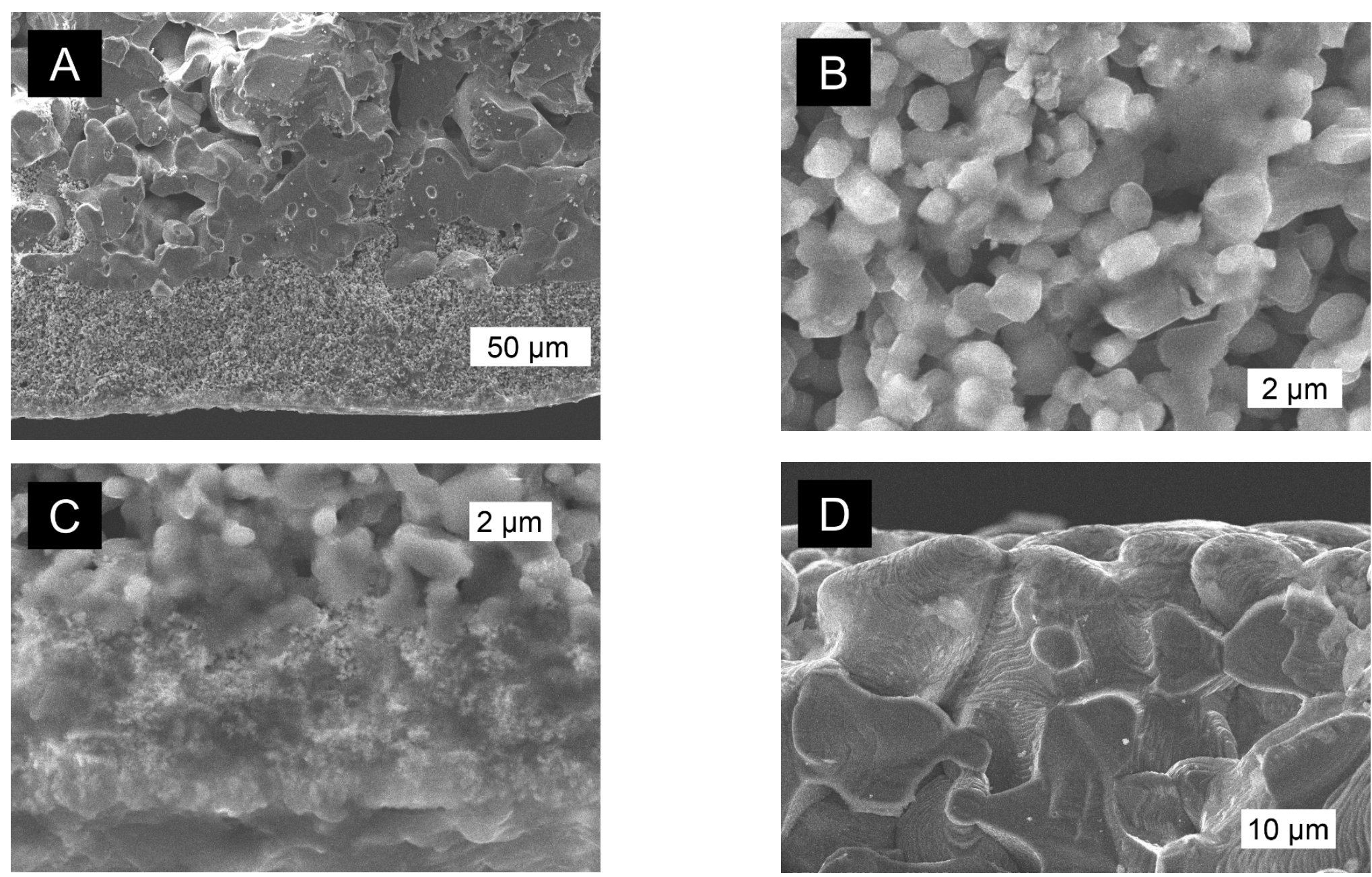

Figure 4: Cross-sectional SEM images of an uncoated ceramic membrane: $(A)$ the feed side of the membrane showing three district sublayers of different porosities; (B) a close-up image of the second (intermediate) sublayer; (C) a close-up image of the third (lowest porosity) sublayer; (D) the permeate side of the membrane showing the terminal part of the third (highest porosity) sublayer. 
The different types of prepared coatings are summarized in Table 1. Preliminary results indicated the membrane LbL-coated with only a single layer of $\mathrm{TiO}_{2}$ had limited photoactivity and UV dead-end filtration experiments were not continued with this membrane. Thus data on MB degradation in membrane reactors are reported only for the membranes with 1-layer or 2-layer PECVD coatings and for membranes with 5-layer LbL coating.

Table 1: Types of photocatalytic coatings prepared on glass slides and ceramic membranes.

\begin{tabular}{|c|c|c|c|c|}
\hline $\begin{array}{l}\text { Coating } \\
\text { method }\end{array}$ & Catalyst & $\begin{array}{c}\text { Number of } \\
\text { catalyst layers }\end{array}$ & Testing & Substrate \\
\hline \multirow{2}{*}{ LbL } & \multirow{2}{*}{ Evonik P25 } & 1 & batch reactor & \multirow{4}{*}{$\begin{array}{l}\text { glass slides } \\
\text { and ceramic } \\
\text { membranes }\end{array}$} \\
\hline & & 5 & \multirow{3}{*}{ membrane reactors } & \\
\hline \multirow{2}{*}{ PECVD } & \multirow{2}{*}{ PECVD-generated } & 1 & & \\
\hline & & 2 & & \\
\hline
\end{tabular}

\subsection{Membrane coatings deposited by the layer-by-layer method}

\subsubsection{Layer-by-layer deposition of $\mathrm{TiO}_{2}$ nanoparticles on glass slides}

The polyelectrolyte systems employed in LbL self-assembly were PAH+PSS and 
PDADMAC+PAA. The main difference between the two systems is the degree of dissociation of the terminating polyelectrolyte. PSS is a strong polyelectrolyte and fully dissociates in solution. In contrast, PAA is weak polyelectrolyte with the degree of dissociation dependent on solution $\mathrm{pH}$. The initiating polyelectrolytes layers also differ: PAH is a weak polyelectrolyte while PDADMAC is a strong polyelectrolyte. Preliminary coating experiments were performed with glass slides as deposition substrates. Figure $5 \mathrm{~A}$ shows an SEM image of the $[\mathrm{PAH} / \mathrm{PSS}]_{4} \mathrm{TiO}_{2}$ coating on a glass slide. The coating technique resulted in a sub-monolayer deposition of $\mathrm{TiO}_{2}$. Using an image processing software (ImageJ), the deposited particle radius was estimated to be $\sim 20 \mathrm{~nm}$. This is slightly larger than reported values for Evonik P25, indicating either a measurement error or possibly aggregates consisting of several particles [25]. This morphology is in contrast to previously reported thin film morphologies of [PAH/PSS] $\mathrm{TiO}_{2}$, which showed dense layers of the catalyst [26]. The difference may be attributed to the lower $\mathrm{pH}$ (2.1) of the catalyst suspension used in our study - a lower $\mathrm{pH}$ increases electrostatic repulsion between $\mathrm{TiO}_{2}$ nanoparticles [27].

Figures $5 B$ to $5 D$ show coatings prepared using PDADMAC and PAA. Experiments using a catalyst suspension with a $0.01 \mathrm{M}$ ionic strength resulted in large surface aggregation (Figure 5B). The impact of $\mathrm{pH}$ of the polyelectrolyte deposition solution on the morphology of $\mathrm{TiO}_{2}$ coating is shown in Figures $5 \mathrm{C}(\mathrm{pH} 2.5)$ and $5 \mathrm{D}(\mathrm{pH} 5)$. In both cases, the pH of the $\mathrm{TiO}_{2}$ suspension was matched to that of the PAA solution. 
The lower $\mathrm{pH}$ system $(\mathrm{pH} 2.5)$ results in a denser coating. Over this $\mathrm{pH}$ range the degree of PAA ionization increases from approximately $20 \%$ at pH 2.5 to $40 \%$ at $\mathrm{pH} 5$ [2]. Since pH 2.5 leads to a denser coating even with a less ionized polyelectrolyte, the higher charge on the catalyst at pH 2.5 appears to control coating density.
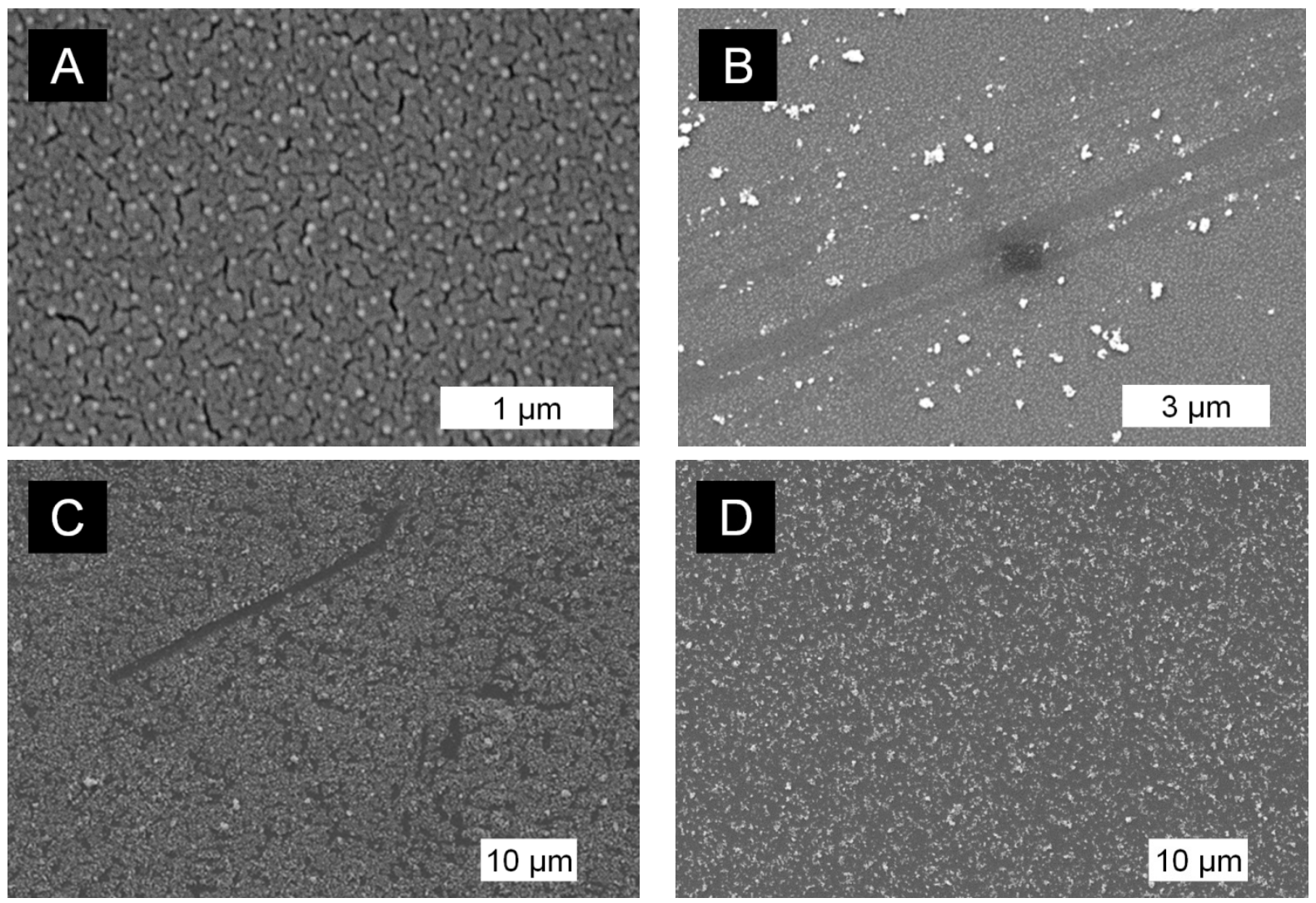

Figure 5: Representative SEM images of glass slides coated by $\mathrm{TiO}_{2}$ nanoparticles using the $\mathrm{LbL}$ method with different polyelectrolyte multilayer films as binder layers:
A) $[\mathrm{PAH} / \mathrm{PSS}]_{4} \mathrm{TiO}_{2}$;
B) $[\mathrm{PDADMAC} / \mathrm{PAA}]_{4} \mathrm{TiO}_{2}$ with catalyst in $0.01 \mathrm{M}$ ionic strength solution;
C) $[\mathrm{PDADMAC} / \mathrm{PAA}]_{4} \mathrm{TiO}_{2}$ with PAA and $\mathrm{TiO}_{2} \mathrm{pH} 2.5$;
D) $[\mathrm{PDADMAC} / \mathrm{PAA}]_{4} \mathrm{TiO}_{2}$ with $\mathrm{PAA}$ and $\mathrm{TiO}_{2} \mathrm{pH} 5$;

\subsubsection{Layer-by-layer deposition of $\mathrm{TiO}_{2}$ nanoparticles on a porous membrane}

Ceramic membranes were coated with $[\mathrm{PDADMAC} / \mathrm{PAA}]_{4}$ at $\mathrm{pH} 5$ and then exposed 
to $\mathrm{TiO}_{2}$ suspension at the same pH. Figures 6C and 6D show SEM images of the ceramic membrane with the resulting $[\mathrm{PDADMAC} / \mathrm{PAA}]_{4} / \mathrm{TiO}_{2}$ coating. Compared with the coating on glass slides (Figure 5D), the coating on the membrane surface is more heterogeneous, with both well-coated and uncoated areas present. SEM images of an uncoated membrane (Figures $6 \mathrm{~A}$ and $6 \mathrm{~B}$ ) are provided as a comparative basis. Supplemental Material (SM) contains additional SEM images of the permeate side of uncoated (Figure S2) and LbL-coated (Figure S3) membranes. Based on SEM images, the average pore size of the support was estimated to be $\sim 1.8 \mu \mathrm{m}$. Local aggregation and pore bridging is occasionally observed. Mostly, however, the coating is sub-monolayer, penetrating into pores to some depth.

\subsection{Membrane coatings deposited by the plasma-enhanced CVD method}

SEM images of PECVD membrane coatings are shown in Figure 6E and 6F. SM contains additional SEM images of the permeate side of PECVD-coated (Figure S4) membranes. The coating has a morphology distinctly different from that of the underlying surface of the membrane materials (Figures 6A and 6B). The coating covers grains of the support but does not bridge the pores or form a continuous film. The morphology appears to be optimal for preserving permeability of the membranes. As in the case with the LbL coating, the extent of coating penetration into pores could not be readily quantified. 

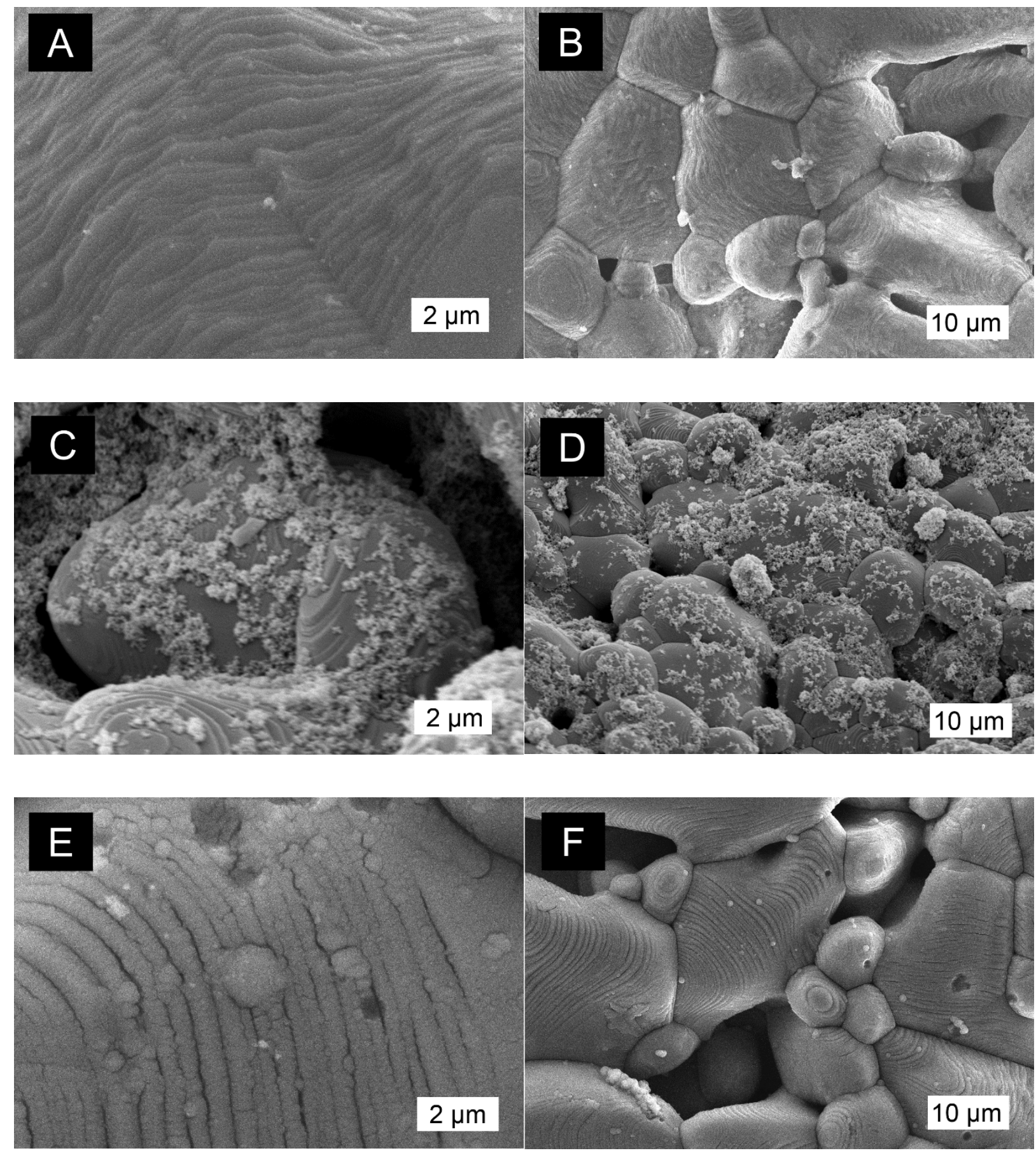

Figure 6: SEM images of the support side of an uncoated ceramic membrane $(A$, B); a membrane coated with $\mathrm{TiO}_{2}$ nanoparticles (80\% anatase, $20 \%$ rutile) by the $\mathrm{LbL}$ method using [PDADMAC/PAA] $]_{4}$ polyelectrolyte multilayer as the binder (C, D); and a membrane coated with 2 layers of $\mathrm{TiO}_{2}$ (100\% anatase after annealing) by the PECVD method (E, F). 


\subsection{Photocatalytic oxidation of Methylene Blue in a batch reactor}

Batch experiments with MB were performed with Evonik P25 catalyst and PECVD-generated catalyst. The initial concentration of MB was approximately 2 $\mathrm{mg} / \mathrm{L}$ in all tests. There was limited MB degradation in batch experiments performed without catalyst (-ロ-, Figure 7). A catalyst loading of $10 \mathrm{mg} / \mathrm{L}$ was used in experiments with P25 and $17 \mathrm{mg} / \mathrm{L}$ was used for experiments with PECVD-generated catalyst. These loadings were chosen to result in a measurable degradation of MB, while not creating an opaque solution that would shield UV irradiation. Prior to the addition of $\mathrm{MB}$, the particle size distribution for each catalyst was measured by light scattering. The average diameter of suspended P25 catalyst was $268 \pm 14 \mathrm{~nm}$. This is approximately 10 times larger than reported values for individual P25 particles indicating that the scrapped catalyst could not be broken down to smaller sizes during sonication. The average diameter of suspended PECVD catalyst was $6.7 \pm 3.3 \mu \mathrm{m}$, significantly larger than P25. Both catalytic reactions followed a linear natural log dependence on time, indicating pseudo-first order reaction kinetics. From Figure 7, it appears that P25 is more photocatalytically active than PECVD catalyst; however, after normalizing each first order reaction constant by the corresponding specific surface area of the catalyst in the reactor(see eq. (4)), the two catalysts are shown to have similar photoactivity. The normalized first order reaction constants are $8.0 \cdot 10^{-3}$ $\pm 1.5 \cdot 10^{-3} \mathrm{~L} /\left(\mathrm{m}^{2} \cdot \mathrm{s}\right)$ and $6.0 \cdot 10^{-3} \pm 0.0 \mathrm{~L} /\left(\mathrm{m}^{2} \cdot \mathrm{s}\right)$ for P25 and PECVD-generated catalysts, respectively. Batch testing for PECVD-generated catalyst was only done 
once, due to a limited quantity of powdered catalyst available.

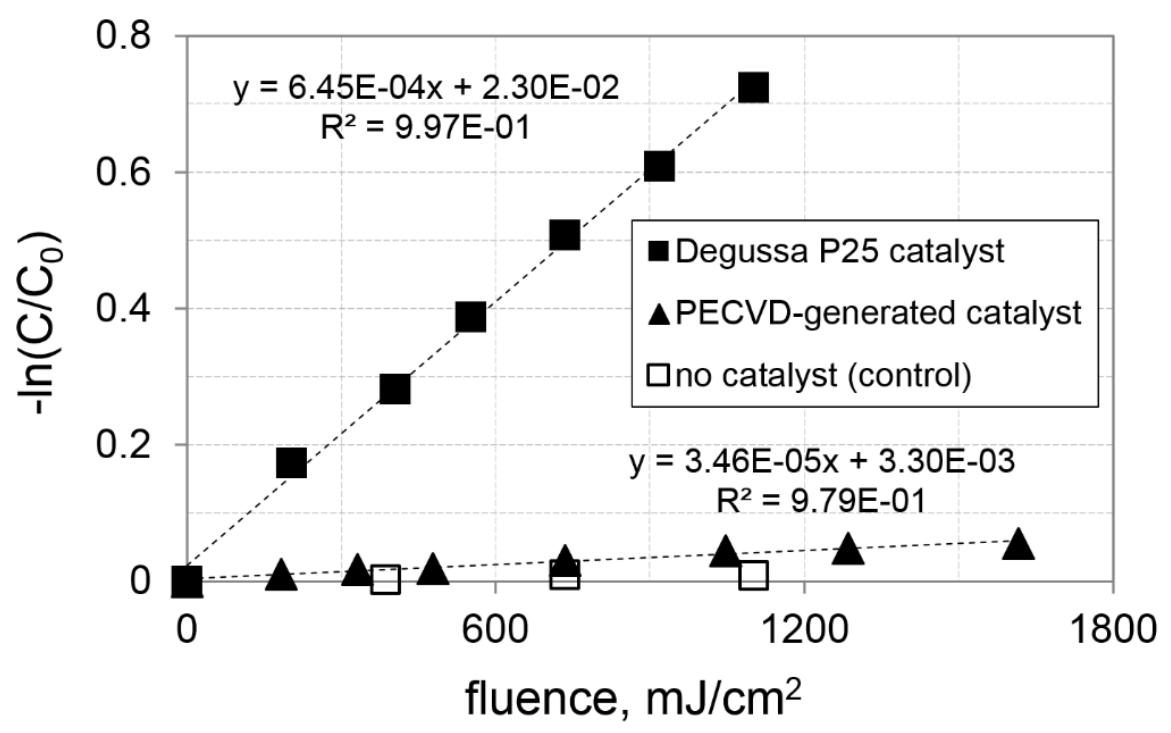

Figure 7: Photocatalytic degradation of Methylene Blue in batch experiments with $10 \mathrm{mg} / \mathrm{L}$ Evonik P25 catalyst (average particle size $268 \mathrm{~nm}$ ) and $17 \mathrm{mg} / \mathrm{L}$ PECVD-generated catalyst (average particle size $6.7 \mu \mathrm{m}$ ).

\subsection{Permeability of membranes coated with $\mathrm{TiO}_{2}$ by $\mathrm{LbL}$ and PECVD methods}

The permeability of the membranes before and after applying the LBL and PECVD coatings was compared using clean water flux tests (Figure 8). In all experiments, 
A

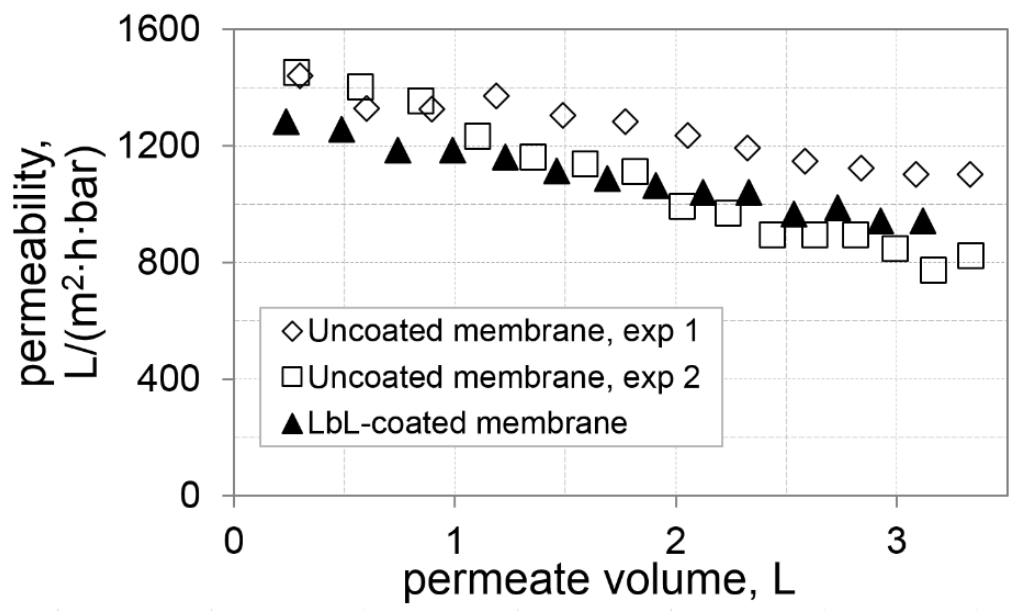

B

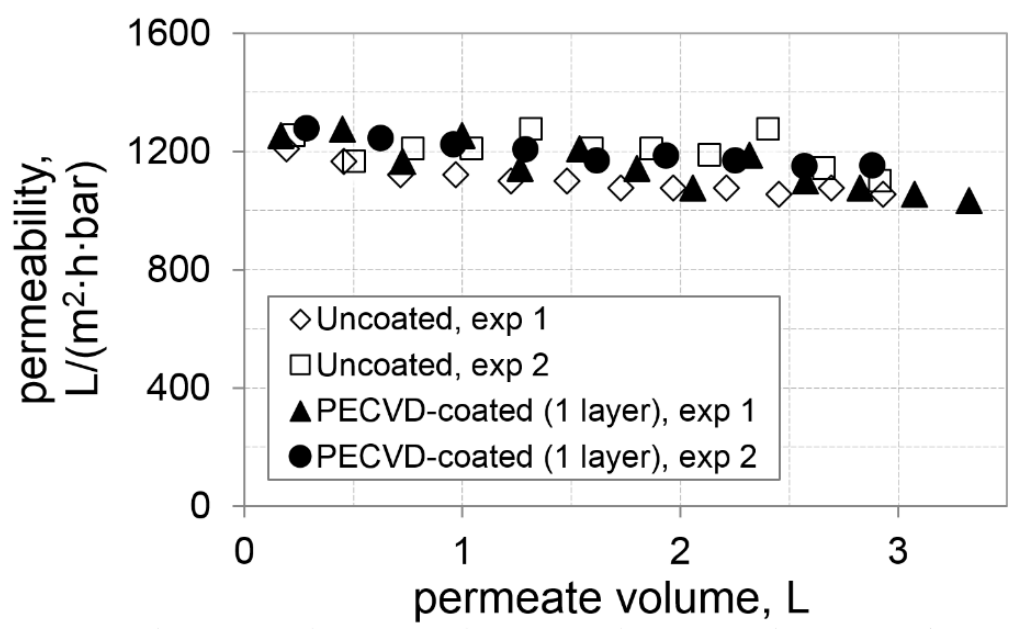

C

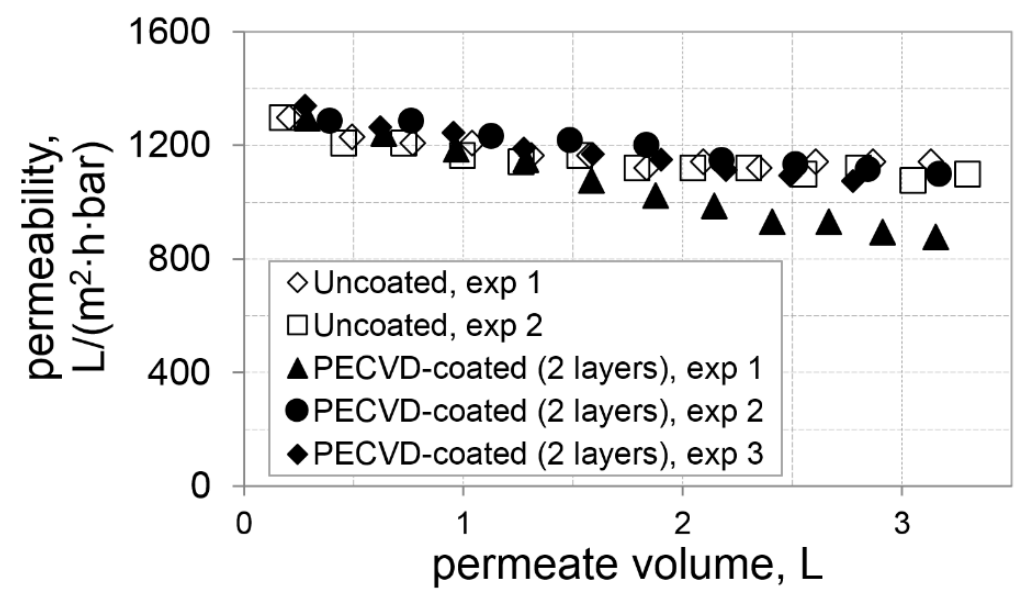

Figure 8: Clean water flux tests with photocatalytic membranes coated with A) 5 layers of $\mathrm{TiO}_{2}$ by the $\mathrm{LbL}$ method; $\mathrm{B}$ ) 1-layer of $\mathrm{TiO}_{2}$ by the PECVD method; C) 2 layers of $\mathrm{TiO}_{2}$ by the PECVD method. 
the membranes permeability decreased with time. As this test was performed with clean DI water, this decrease in permeability for both the coated and uncoated membranes was attributed to permeation-induced changes in the membrane structure, and not to fouling. Similar declines in pure water permeability of ceramic membranes have been reported previously (e.g. [2, 15, 28]). As is clear from Figure 8, neither PECVD nor LbL coatings appeared to decrease membrane permeability.

\subsection{Photocatalytic oxidation of Methylene Blue in a photocatalytic membrane reactor. Analysis of membrane performance}

Comparison of the photocatalytic efficiency of the PECVD-coated and LbL-coated membranes was performed using UV dead-end filtration experiments with MB as the probe compound. Each experiment was repeated three times under the same conditions. MB degradation showed strong linear correlation with the inverse of flow rate, which is proportional to MB residence time in the membrane (Figure 9). Table 2 summarized reactive flux values extracted from the data (eq. (9b)) and corresponding standard deviations.

Comparison of the photocatalytic efficiency of the two types of coating, with $\alpha=0.1$, shows that the LbL-coated membrane has a significantly higher photocatalytic activity than the 1-layer PECVD membrane. There is no statistically significant difference between the 1-layer and 2-layer PECVD-coated membranes. Similarly, 2-layer 
PECVD-coated and LbL-coated membranes are not significantly different.

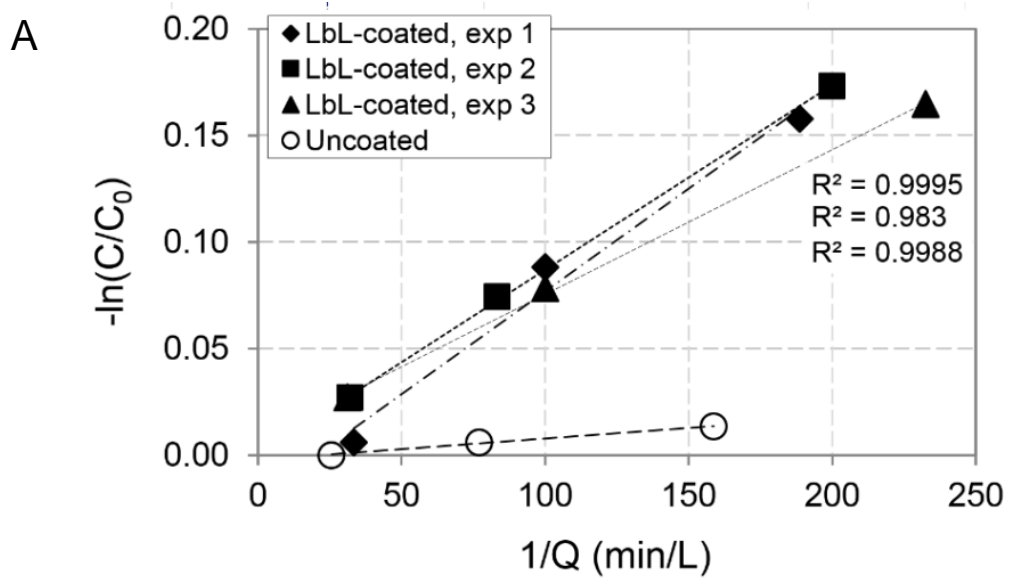

B

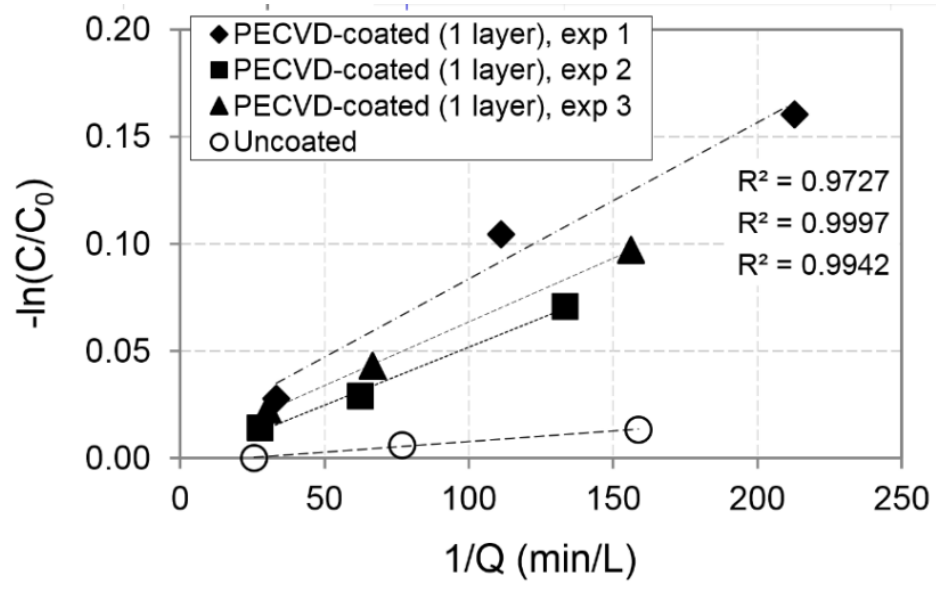

C

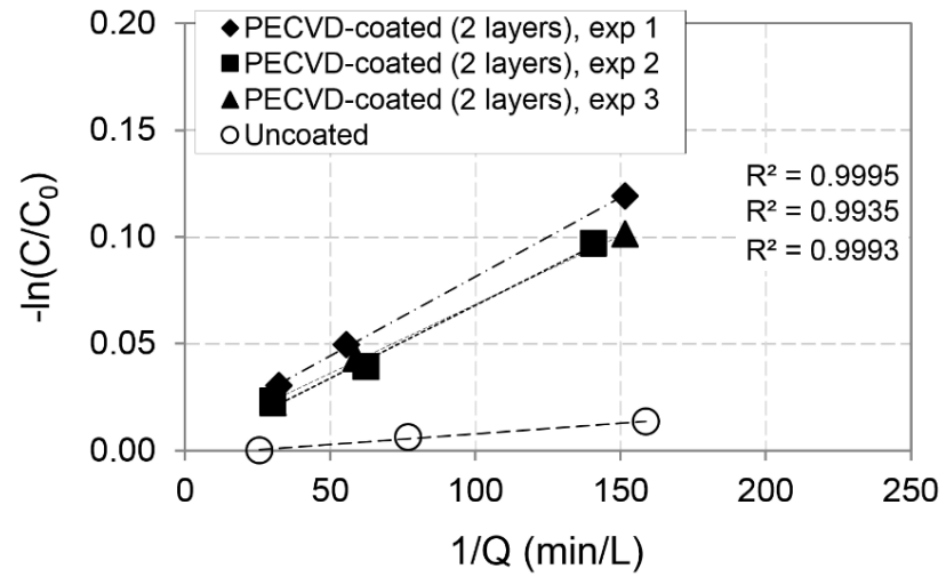

Figure 9: $\quad$ Methylene blue degradation in a photocatalytic membrane reactor with a flat disk membrane $\left(d_{\text {pore }}=0.14 \mu \mathrm{m}\right)$ operated in a dead-end configuration and coated with $\mathrm{TiO}_{2}$ photocatalyst by three different procedures: A) 5-layers coating by the LbL technique; B) 1-layer coating by PECVD, and C) 2-layers coating by PECVD. 
Table 2: Reactivity (measured) and geometrical characteristics (calculated) of photocatalytic coatings self-assembled by the LbL method and deposited by the PECVD method. The last column provides data normalized with respect to PECVD-2 coating. Errors correspond to standard deviations.

\begin{tabular}{|c|c|c|c|c|c|c|c|}
\hline \multicolumn{3}{|c|}{ Coating } & \multirow{2}{*}{$\begin{array}{l}\text { Reactive flux } \\
\boldsymbol{\eta} 10^{-4}, \mathrm{~m} / \mathrm{s} \\
7.41 \pm 0.23\end{array}$} & \multirow{2}{*}{$\begin{array}{l}\text { Average } \\
\text { reactive flux } \\
\bar{\eta} 10^{-4}, \mathrm{~m} / \mathrm{s}\end{array}$} & \multirow{2}{*}{$\begin{array}{c}2^{\text {nd }} \text { order reaction } \\
\text { rate constant } \\
\boldsymbol{k}^{\prime \prime} \cdot 10^{-3}, \text { units }\end{array}$} & $\begin{array}{l}\text { Normalized } \\
\text { reactive flux } \\
\frac{\eta}{k^{\prime \prime}} \cdot 10^{-1}, \text { units }\end{array}$ & \multirow{2}{*}{$\frac{\boldsymbol{\theta}_{x} \boldsymbol{l}_{\boldsymbol{x}}}{\boldsymbol{\theta}_{\boldsymbol{y}} \boldsymbol{l}_{\boldsymbol{y}}}$} \\
\hline \multirow{3}{*}{\multicolumn{2}{|c|}{ 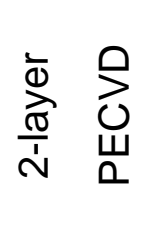 }} & membrane 1 & & & & \multirow{3}{*}{$1.15 \pm 0.08$} & \\
\hline & & membrane 2 & $6.82 \pm 0.77$ & \multirow[t]{2}{*}{$6.89 \pm 0.49$} & \multirow[t]{2}{*}{$6.0 \pm 0.0$} & & \multirow[t]{2}{*}{$1.00 \pm 0.10$} \\
\hline & & membrane 3 & $6.44 \pm 0.25$ & & & & \\
\hline & \multirow{3}{*}{ 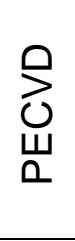 } & membrane 1 & $7.30 \pm 1.74$ & \multirow{3}{*}{$6.22 \pm 0.97$} & \multirow{3}{*}{$6.0 \pm 0.0$} & \multirow{3}{*}{$1.04 \pm 0.16$} & \multirow{3}{*}{$0.90 \pm 0.15$} \\
\hline & & membrane 2 & $5.42 \pm 0.57$ & & & & \\
\hline & & membrane 3 & $5.95 \pm 0.14$ & & & & \\
\hline \multirow{3}{*}{\multicolumn{2}{|c|}{$\frac{\frac{\bar{d}}{\frac{\sigma}{1}}}{\text { ம }}$}} & membrane 1 & $8.90 \pm 2.10$ & \multirow{3}{*}{$8.10 \pm 1.18$} & \multirow{3}{*}{$7.9 \pm 0.8$} & \multirow{3}{*}{$1.03 \pm 0.18$} & \multirow{3}{*}{$0.89 \pm 0.17$} \\
\hline & & membrane 2 & $8.66 \pm 0.27$ & & & & \\
\hline & & membrane 3 & $6.74 \pm 0.27$ & & & & \\
\hline
\end{tabular}


Although LbL coating shows higher average removal of the model pollutant (i.e. higher $\eta)$ than 1-layer PECVD coating, normalized reactive fluxes $\left(\eta / k^{\prime \prime}\right)$ for these two coating types are statistically the same. This, the higher rate of removal seen with LbL self-assembly is attributed to the higher catalyst efficiency of P25 in comparison with PECVD-generated catalyst. Conversely, despite the lower catalyst efficiency (i.e. lower $k^{\prime \prime}$ ), PECVD-coating shows similar normalized reactive fluxes $\left(\eta / k^{\prime \prime}\right)$ pointing to the reaction zone geometry superior to that of the LbL coating.. The above analysis points to pathways for improving each coating technique. The LbL method should target increasing the amount of catalyst in the reactive zone or making the reaction zone deeper. In contrast, PECVD should focus on increasing catalyst efficiency, possibly employing new materials for deposition. While this study analyzed two coating techniques using the same substrate, a similar comparison can be made to find the optimal substrate geometry by coating different substrates with the same coating technique.

From the measured values of $C / C_{0}$ as a function of permeate flow rate (Figure 9), it is also possible to evaluate the parameter $\delta_{M B}$, the rate of MB decomposition normalized by the membrane surface area [9]. The value of $\delta_{M B}$ is $4 \cdot 0 \cdot 10^{-8} \pm$ $1.0 \cdot 10^{-8}, 4.6 \cdot 10^{-8} \pm 0.7 \cdot 10^{-8}$, and $5.2 \cdot 10^{-8} \pm 0.8 \cdot 10^{-8} \mathrm{~mol} /\left(\mathrm{m}^{2} \cdot \mathrm{s}\right)$, for the membranes coated with1-layer PECVD, 2-layers PECVD and 5-layers LbL, respectively. These values are of the same order of magnitude as those we previously reported for $\mathrm{TiO}_{2}$-based membranes prepared by the sol-gel route $[7,8]$ and other ceramic 
supports modified by the PECVD [9] routes, as well as those that Li et. al. measured for Ag-titania-polymer composite membranes [29].

\section{Conclusions}

A sub-mono layer fabrication technique using LbL self-assembly has been developed for deposition of titanium dioxide photocatalyst on microporous ceramic membrane support structures. The resulting photocatalytic layers do not reduce the membrane permeability. In comparison with membranes coated by the PECVD process developed earlier, the LbL-coated membranes have a higher average rate of pollutant removal during UV dead-end filtration experiments. The relative coating quality is evaluated by normalizing the reactive flux $(\eta, \mathrm{m} / \mathrm{s})$ measured in dead-end filtration tests by the reaction rate constant determined in batch tests with the same catalyst that was used to coat the membranes. The novelty of the approach is in relating coating's photocatalytic properties ( $\eta$ and the normalized catalytic activity of the catalyst $\left.\left(k^{\prime \prime}, \mathrm{m} / \mathrm{s}\right)\right)$ to the reactor's geometry expressed in terms of the length of the reaction zone $\left(l^{r z}, \mathrm{~m}\right)$ and coating density $(\theta)$. The proposed modeling approach can be used to compare two types of coating. Both LbL and PECVD coating techniques result in a similar coating quality as witnessed by similar values of $\eta / k^{\prime \prime}$ (or, equivalently, similar values of $\theta l^{r z}$ ). The higher rate of removal seen with LbL self-assembly is attributed to the improved catalyst efficiency of P25. This analysis points to pathways for improving each coating technique. The LbL method should 
target increasing the catalyst coverage or depth of the reaction zone or both In contrast, PECVD, with its lower catalyst reactivity, should focus on increasing catalytic efficiency possibly by employing new catalyst materials or dopants.

\section{Acknowledgements}

This material is based upon work supported in part by the National Science Foundation Partnerships for International Education and Research program under Grant IIA-1243433 and in part by a strategic partnership grant from the Center for European, Russian, and Eurasian Studies at Michigan State University.

The Doctorate of Ming Zhou was financed by the scholarship of European Commission - Education, Audiovisual and Culture Executive Agency (EACEA) under the program "Erasmus Mundus Doctorate in Membrane Engineering" (EUDIME, FPA No. 2011-0014, Edition I, http://eudime.unical.it). 


\section{List of Symbols}

$\delta_{M B}$ the rate of MB decomposition normalized by the membrane surface area, $\mathrm{mol} \cdot\left(\mathrm{m}^{2} \cdot \mathrm{s}\right)^{-1}$

$\varepsilon \quad$ molar absorption coefficient, L. $\mathrm{mol}^{-1} \cdot \mathrm{cm}^{-1}$

$\eta \quad$ reactive flux in a plug flow reactor with reaction of the $1^{\text {st }}$ order, $\mathrm{m} \cdot \mathrm{s}^{-1}$

$\theta$ ratio of the surface area of the catalyst to the total surface area in the reaction zone

$\rho_{\mathrm{TiO}_{2}}$ density of the catalyst, $\mathrm{kg} \cdot \mathrm{m}^{-3}$

$\Phi \quad$ quantum yield, $\mathrm{mol}^{-E^{-1}}{ }^{-1}$

A optical absorbance

a radius of the spherical catalyst particle, $\mathrm{m}$

$C_{0} \quad \mathrm{MB}$ concentration in the feed, $\mathrm{mol} \cdot \mathrm{m}^{-3}$

$C_{p} \quad \mathrm{MB}$ concentration in the permeate, $\mathrm{mol} \cdot \mathrm{m}^{-3}$

$d_{\text {pore }} \quad$ nominal pore size of the membrane, $\mathrm{m}$

$F \quad$ fluence, $\mathrm{J} \cdot \mathrm{cm}^{-2}$

$K_{b} \quad 2^{\text {nd }}$ order reaction rate constant in the batch reactor, $\mathrm{L} \cdot\left(\mathrm{M}_{\mathrm{ROS}} \cdot \mathrm{s}\right)^{-1}$

$k_{b}^{\prime} \quad 1^{\text {st }}$ order reaction constant in the batch reactor, $\mathrm{s}^{-1}$

$k^{\prime \prime} \quad 1^{\text {st }}$ order reaction constant in the batch reactor, normalized by the specific surface area of photocatalyst, $\mathrm{m} \cdot \mathrm{s}^{-1}$

$k_{p f} \quad 1^{\text {st }}$ order reaction constant in the plug-flow membrane reactor, $\mathrm{s}^{-1}$

$l^{r z} \quad$ length of the reaction zone, $\mathrm{m}$

$l \quad$ optical path length, $\mathrm{m}$

$M_{\mathrm{TiO}_{2}} \quad$ catalyst loading in the reactor, $\mathrm{kg}$

$Q \quad$ permeate flow rate, $\mathrm{m}^{3} \cdot \mathrm{s}^{-1}$

$S_{b} \quad$ surface area of photocatalyst in the batch reactor, $\mathrm{m}^{2}$

$s_{b} \quad$ specific surface area of photocatalyst in the batch reactor, $\mathrm{m}^{2} \cdot \mathrm{m}^{-3}$

$s_{p f} \quad$ specific surface area of photocatalyst in the batch reactor, $\mathrm{m}^{2} \cdot \mathrm{m}^{-3}$

$S_{r z} \quad$ total surface area of the reaction zone, $\mathrm{m}^{2}$ 
$V_{b} \quad$ volume of the batch reactor, $\mathrm{m}^{3}$

$V_{r z} \quad$ volume of the reaction zone, $\mathrm{m}^{3}$

$Y \quad$ catalytic yield of reactive oxygen species per surface area of catalyst, $\mathrm{M}_{\mathrm{ROS}} \cdot \mathrm{m}^{-2}$ 


\section{List of Figures}

Figure 1 Schematic illustration of a cross-section of an asymmetric ceramic membrane with the permeate side coated by catalytic nanoparticles and exposed to UV light for flow-through photocatalysis.

Figure 2 Schematic representation of a cylindrical pore of diameter $d_{\text {pore }}$ covered with catalyst particles of diameter $2 a$ to form a reaction zone of depth $l^{r z}$. Reaction zone is defined as the part of the pore where both photocatalyst and light are present.

Figure 3 UV batch reactor (A) and photocatalytic membrane reactor (B) used to evaluate photocatalyst efficiency and performance of the UV-microfiltration hybrid process.

Figure 4 Cross-sectional SEM images of an uncoated ceramic membrane: $(A)$ the feed side of the membrane showing three district sublayers of different porosities; (B) close-up image of the second (intermediate) sublayer; (c) close-up image of the third (lowest porosity) sublayer; (C) the permeate side of the membrane showing the terminal part of the third (highest porosity) sublayer.

Figure 5 SEM images of glass slides coated by $\mathrm{TiO}_{2}$ nanoparticles using the LbL method with different polyelectrolyte multilayer films as binder layers:
A) $[\mathrm{PAH} / \mathrm{PSS}]_{4} \mathrm{TiO}_{2}$;
B) $[\mathrm{PDADMAC} / \mathrm{PAA}]_{4} \mathrm{TiO}_{2}$ with catalyst in $0.01 \mathrm{M}$ ionic strength solution; 

C) $[\mathrm{PDADMAC/PAA}]_{4} \mathrm{TiO}_{2}$ with $\mathrm{PAA}$ and $\mathrm{TiO}_{2} \mathrm{pH} 2.5$;
D) $[\mathrm{PDADMAC/PAA}]_{4} \mathrm{TiO}_{2}$ with PAA and $\mathrm{TiO}_{2} \mathrm{pH} 5$;

Figure 6 SEM images of the support side of an uncoated ceramic membrane (A, B); a membrane coated with $\mathrm{TiO}_{2}$ nanoparticles (80 wt\% anatase, 20 wt\% rutile) by the LbL method using [PDADMAC/PAA] $]_{4}$ polyelectrolyte multilayer as the binder (C, D); and a membrane coated with 2 layers of $\mathrm{TiO}_{2}(100 \%$ anatase after annealing) by the PECVD method (E, F).

Figure 7 Photocatalytic degradation of Methylene Blue in batch experiments with $10 \mathrm{mg} / \mathrm{L}$ Evonik P25 catalyst (average particle size $268 \mathrm{~nm}$ ) and 17 mg/L PECVD-generated catalyst (average particle size $6.7 \mu \mathrm{m}$ ).

Figure 8 Clean water flux tests with photocatalytic membranes coated with A) 5 layers of $\mathrm{TiO}_{2}$ by the LbL method; $\mathrm{B}$ ) 1-layer of $\mathrm{TiO}_{2}$ by the PECVD method; C) 2 layers of $\mathrm{TiO}_{2}$ by the PECVD method.

Figure 9 Methylene blue degradation in a photocatalytic membrane reactor with a flat disk membrane $\left(d_{\text {pore }}=0.14 \mu \mathrm{m}\right)$ operated in a dead-end configuration and coated with $\mathrm{TiO}_{2}$ photocatalyst by three different procedures: A) 5-layers coating by the LbL technique; B) 1-layer coating by PECVD, and C) 2-layers coating by PECVD. 


\section{List of Tables}

Table 1 Types of photocatalytic coatings prepared on glass slides and ceramic membranes.

Table 2 Reactivity (measured) and geometrical (calculated) characteristics of photocatalytic coatings self-assembled by the LbL method and deposited by the PECVD method. The last column provides data normalized with respect to PECVD-2 coating. Errors correspond to $95 \%$ confidence interval. 


\section{References}

[1] S. Mozia, Photocatalytic membrane reactors (PMRs) in water and wastewater treatment. A review, Separ. Purif. Technol., 73 (2010) 71-91.

[2] H.M. Zhang, X. Quan, S. Chen, H.M. Zhao, Y.Z. Zhao, Fabrication of photocatalytic membrane and evaluation its efficiency in removal of organic pollutants from water, Separ. Purif. Technol., 50 (2006) 147-155.

[3] X. Zhang, D.K. Wang, J.C. Diniz da Costa, Recent progresses on fabrication of photocatalytic membranes for water treatment, Catal. Today, 230 (2014) 47-54.

[4] M.N. Chong, B. Jin, C.W.K. Chow, C. Saint, Recent developments in photocatalytic water treatment technology: A review, Water Res., 44 (2010) 2997-3027.

[5] D.F. Ollis, Integrating photocatalysis and membrane technologies for water treatment, Ann. N.Y. Acad. Sci., 984 (2003) 65-84.

[6] A. Zakersalehi, H. Choi, J. Andersen, D.D. Dionysiou, Photocatalytic ceramic membranes, in: E.M.V. Hoek, V.V. Tarabara (Eds.) Encyclopedia of Membrane Science and Technology Wiley, 2013, pp. 1-22.

[7] F. Bosc, A. Ayral, C. Guizard, Mesoporous anatase coatings for coupling membrane separation and photocatalyzed reactions, J. Membr. Sci., 265 (2005) 13-19.

[8] L. Djafer, A. Ayral, A. Ouagued, Robust synthesis and performance of a titania-based ultrafiltration membrane with photocatalytic properties, Separ. Purif. Technol., 75 (2010) 198-203.

[9] M. Zhou, S. Roualdes, A. Ayral, New photocatalytic contactors obtained by PECVD deposition of TiO2 thin layers on the surface of macroporous supports PECVD TiO2-based membranes as photocatalysts, Eur. Phys. J.: Special Topics 224 (2015) 1871-1882.

[10] G.E. Romanos, C.P. Athanasekou, F.K. Katsarosa, N.K. Kanellopoulos, D.D. Dionysiou, V. Likodimos, P. Falaras, Double-side active TiO2-modified nanofiltration membranes in continuous flow photocatalytic reactors for effective water purification, J. Haz. Mater., 211-212 (2012) 304-316.

[11] C.P. Athanasekou, G.E. Romanos, F.K. Katsaros, K. Kordatos, V. Likodimos, P. Falaras, Very efficient composite titania membranes in hybrid ultrafiltration/photocatalysis water treatment processes, J. Membr. Sci., 392 (2012) 192-203. 
[12] G.E. Romanos, C.P. Athanasekou, V. Likodimos, P. Aloupogiannis, P. Falaras, Hybrid ultrafiltration/photocatalytic membranes for efficient water treatment, Ind. Eng. Chem. Res., 52 (2013) 13938-13947.

[13] C.P. Athanasekou, S. Morales-Torres, V. Likodimos, G.E. Romanos, L.M. Pastrana-Martinez, P. Falaras, D.D. Dionysiou, J.L. Faria, J.L. Figueiredo, A.M.T. Silva, Prototype composite membranes of partially reduced graphene oxide/TiO2 for photocatalytic ultrafiltration water treatment under visible light, Appl. Catal. B: Environ., 158-159 (2014) 361-372.

[14] C.P. Athanasekou, N.G. Moustakas, S. Morales-Torres, L.M. Pastrana-Martínez, J.L. Figueiredo, J.L. Faria, A.M.T. Silva, J.M. Dona-Rodriguez, G.E. Romanos, P. Falaras, Ceramic photocatalytic membranes for water filtration under UV and visiblelight, Appl. Catal. B: Environ., 178 (2015) 12-19.

[15] B. Guo, E.V. Pasco, I. Xagoraraki, V.V. Tarabara, Virus removal and inactivation in a hybrid microfiltration-UV process with a photocatalytic membrane, Separ. Purif. Technol., 149 (2015) 245-254.

[16] Z. Ding, X.J. Hu, P.L. Yue, G.Q. Lu, P.F. Greenfield, Synthesis of anatase TiO2 supported on porous solids by chemical vapor deposition, Catal. Today, 68 (2001) 173-182.

[17] T.H. Kim, B.H. Sohn, Photocatalytic thin films containing TiO2 nanoparticles by the layer-by-layer self-assembling method, Appl. Surf. Sci., 201 (2002) 109-114.

[18] A. Sobczyk-Guzenda, B. Pietrzyk, H. Szymanowski, M. Gazicki-Lipman, W. Jakubowski, Photocatalytic activity of thin TiO2 films deposited using sol-gel and plasma enhanced chemical vapor deposition methods, Ceram. Intern., 39 (2013) 2787-2794.

[19] W.Y. Wang, A. Irawan, Y. Ku, Photocatalytic degradation of Acid Red 4 using a titanium dioxide membrane supported on a porous ceramic tube, Water Res., 42 (2008) 4725-4732.

[20] M. Kosmulski, The significance of the difference in the point of zero charge between rutile and anatase Adv. Colloid interface Sci., 99 (2002) 255-264.

[21] C.A. Crock, A.R. Rogensues, W. Shan, V.V. Tarabara, Polymer nanocomposites with graphene-based hierarchical fillers as materials for multifunctional water treatment membranes, Water Res., 47 (2013) 3984-3996.

[22] C.A. Crock, V.V. Tarabara, Pd and Pd-Au nanocatalysts supported on exfoliated graphite for high throughput dehalogenation by nanocomposite membranes, Environ. Sci.: Nano. , (2016).

[23] R.O. Rahn, Potassium iodide as a chemical actinometer for $254 \mathrm{~nm}$ radiation: 
Use of iodate as an electron scavenger, Photochemistry and Photobiology, 66 (1997) 450-455.

[24] R.O. Rahn, P. Xu, S.L. Miller, Dosimetry of room-air germicidal ( $254 \mathrm{~nm}$ ) radiation using spherical actinometry, Photochem. Photobiol., 70 (1999) 314-318.

[25] J.F. Porter, Y.G. Li, C.K. Chan, The effect of calcination on the microstructural characteristics and photoreactivity of Degussa P-25 TiO2, J. Mater. Sci., 34 (1999) 1523-1531.

[26] D.N. Priya, J.M. Modak, A.M. Raichur, LbL fabricated poly(styrene sulfonate)/TiO2 multilayer thin films for environmental applications, Appl. Mater. Interfac., 1 (2009) 2684-2693.

[27] J. Kim, W.Q. Shan, S.H.R. Davies, M.J. Baumann, S.J. Masten, V.V. Tarabara, Interactions of aqueous NOM with nanoscale TiO2: Implications for ceramic membrane filtration-ozonation hybrid process, Environ. Sci. Technol., 43 (2009) 5488-5494.

[28] J. Mendret, M. Hatat-Fraile, M. Rivallin, S. Brosillon, Hydrophilic composite membranes for simultaneous separation and photocatalytic degradation of organic pollutants, Separ. Purif. Technol., 111 ((2013) 9-19.

[29] J.-H. Li, B.-F. Yan, X.-S. Shao, S.-S. Wang, H.-Y. Tian, Q.-Q. Zhang, Influence of $\mathrm{Ag} / \mathrm{TiO} 2$ nanoparticle on the surface hydrophilicity and visible-light response activity of polyvinylidene fluoride membrane, Appl. Surf. Sci., 324 (2015) 82-89. 
$\mathrm{TiO}_{2}$ coating via layer-by-layer assembly

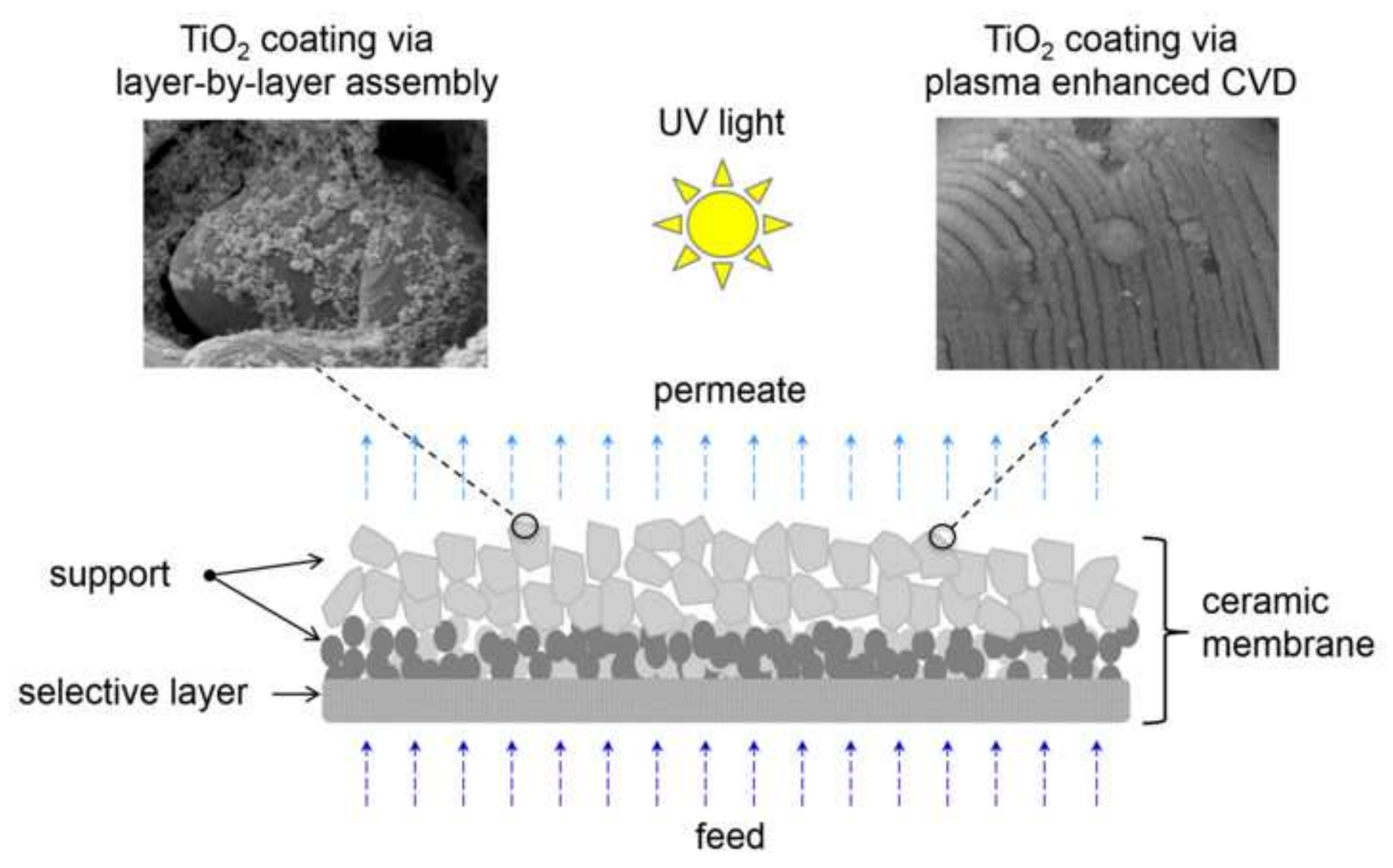

$\mathrm{TiO}_{2}$ coating via plasma enhanced CVD 